Int. J. Electrochem. Sci., 13 (2018) 9731 - 9741

\title{
Effect of Microstructure on Corrosion Resistance of Anodic Oxidation Coatings on TA2 Commercially Pure Titanium in Sodium-Tartrate Solution
}

\author{
Xiao Wang, Ju Rong ${ }^{*}$, Yuhan Yao, Jing Feng, Yannan Zhang, Xiaohua Yu*, Zhaolin Zhan \\ Faculty of Materials Science and Engineering, Kunming University of Science and Technology, \\ Kunming, 650093, China \\ *E-mail: JRong_kmust@163.com; xiaohua_y@163.com
}

doi: $10.20964 / 2018.10 .27$

Received: 25 May 2018 / Accepted: 17 July 2018 / Published: 1 September 2018

Titanium anodic oxide films were prepared using a constant-potential method in a sodium-tartrate environmentally friendly electrolyte at different concentrations $\left(1,5,15,30\right.$ and $\left.50 \mathrm{~g} \mathrm{~L}^{-1}\right)$. The microstructure, elemental composition, and microscopic three-dimensional morphology of the film were analyzed by scanning electron microscopy, energy-dispersive spectrometry, and atomic force microscopy. The polarization curve and electrochemical impedance spectroscopy of the sample at a low potential in $3.5 \% \mathrm{NaCl}$ solution were studied by using an electrochemical workstation. The effect of the microscopic three-dimensional morphology on the corrosion resistance was discussed. The surface morphology of the oxide film indicates that a uniform and complete oxide film with a lower roughness can be obtained in the $15 \mathrm{~g} \mathrm{~L}^{-1}$ sodium-tartrate solution concentrations. As the sodiumtartrate electrolyte concentrations increases, the depths of the cracks deepen and the size of the raised bulges increases. The resulting oxide film has a wide passivation region of 0 to $4 \mathrm{~V}$, a maximum polarization resistance, a small passivation-induced current value, and a low corrosion current value of $3.730 \times 10^{-5} \mathrm{~A} \cdot \mathrm{cm}^{-2}$, and thus, it exhibits an excellent corrosion resistance, and a wide range of potential applications, such as in biological technologies. This work provides a new approach to prepare environmentally friendly, non-polluting titanium anodic oxide films and proposes a novel design to adjust the corrosion resistance performance of the anodized film.

Keywords: TA2 pure titanium; anodic oxidation; corrosion resistance; atomic force microscopy

\section{FULL TEXT}

(C) 2018 The Authors. Published by ESG (www.electrochemsci.org). This article is an open access article distributed under the terms and conditions of the Creative Commons Attribution license (http://creativecommons.org/licenses/by/4.0/). 